\title{
EDITORIAL
}

\section{El derecho del trabajo en la posmodernidad}

Agradezco infinitamente al doctor Calos Villabella la invitación que hace algún tiempo me realizara con la finalidad de colaborar como editor huésped en la prestigiada REVISTA IUS para coordinar un número dedicado al derecho del trabajo, lo cual acepté. Para tal fin, se invitó a diversos abogados e investigadores de lberoamérica y se seleccionó como tema central el derecho del trabajo en la posmodernidad. Esto se debió a los cambios que se generan a nivel global en esta rama del derecho, específicamente por las tecnologías utilizadas en la tercera revolución industrial y que necesariamente requerian un análisis respecto a los paradigmas tradicionales del derecho del trabajo, así como de los nuevos retos que estas tecnologías disruptivas generan en el ámbito jurídico.

En la actualidad nos encontramos en una segunda etapa de la tercera revolución industrial. Algunos, sin embargo, consideran que estamos en la cuarta revolución industrial, en virtud de las variadas tecnologías, como la robótica, la inteligencia artificial, el cómputo en la nube, internet de las cosas, entre otras. Como se ha manifestado en Alemania, esto expresa que en realidad estamos ya en presencia de la industria 4.0.

En un sentido más amplio, principalmente los países de oriente consideran que los derechos de los trabajadores y de ciudadanos en general deberán cambiar y analizarse en forma interdisciplinaria y transversal, en virtud del impacto que tienen dichas tecnologías en lo que ellos denominan sociedad 5G.

El análisis de este tema central, como corriente filosófica, busca nuevas formas de pensamiento orientado en el crecimiento del individuo a través del uso de la tecnología. Por esta razón, varios de los temas que se abordan en este número consideran los derechos del trabajador y del patrón en forma transversal en virtud de generar nuevos retos para el derecho laboral.

En este número contamos con artículos que hacen referencia a los derechos de los trabajadores en la sociedad 5G: el respeto a los derechos fundamentales inespecíficos en el ámbito laboral relacionados con el derecho de intimidad del trabajador y el impacto de estos desde una perspectiva de responsabilidad social de la empresa.

Por último, deseo agradecer al equipo editorial de la REVISTA IUS por invitarme y acogerme como editor huésped en este número dedicado al fascinante tema del derecho del trabajo, así como mi gratitud a los investigadores de países como España, Colombia, Cuba, Chile, Perú y México que colaboran en el mismo. Gracias al análisis de sus artículos se cumple con el objetivo de la investigación jurídica y el análisis del derecho laboral desde una nueva perspectiva transversal en temas de actualidad y de vanguardia.

*Felipe Miguel Carrasco Fernández

Universidad Popular Autónoma del Estado de Puebla

\footnotetext{
* Investigador de la Universidad Popular Autónoma del Estado de Puebla (Upaep) México. Miembro del Sistema Nacional De Investigadores Conacyt.
} 